\title{
Classical conditioning of the nictitating membrane response of the lemon shark (Negaprion brevirostris)
}

\author{
SAMUEL H. GRUBER and NEIL SCHNEIDERMAN \\ University of Miami, Miami, Florida $\$ 3149$
}

\begin{abstract}
An experimental group of lemon sharks received 100 daily presentations of light flash as the conditioned stimulus (CS) and electric shock as the unconditioned stimulus (US) in a classical conditioning situation. The conditioned responses (CRs) and unconditioned responses (URs) under observation consisted of extensions of the nictitating membrane. Separate control groups received either (a) no CS or US, (b) CS-alone, or (c) completely random presentations of CS and US. Few CRs occurred in the experimental group at the outset of conditioning, but the percentage of CRs during the second half of the first acquisition session exceeded $95 \%$. Conditioning stabilized above $95 \%$ CRs during Acquisition Sessions 3 through 7 . These responses could not be attributed to pseudoconditioning, sensitization, or other nonassociative factors. When the experimental group was subsequently given six CS-alone sessions, the course of extinction was gradual. Most results seemed similar to those previously obtained during classical conditioning of the nictitating membrane in rabbits.
\end{abstract}

Sharks have been used extensively as subjects for comparative anatomical and physiological investigations of vertebrates but have only rarely been studied in behavioral experiments. Several investigators (e.g., Aronson, Aronson \& Clark, 1967; Clark, 1959; Graeber \& Ebbesson, 1972; Nelson, 1967) have instrumentally conditioned sharks, but controlled studies of classical conditioning of sharks have not yet been reported. Systematic studies of classical as well as instrumental conditioning of sharks, however, offer the potential of providing information about the sensory capability of sharks and about the evolution of brain function and learned behavior.

At the outset of the present experiment, the lemon shark appeared to be particularly suitable for studying classical conditioning in sharks. First, it is widely available in Florida coastal waters. Second, it is easily maintained in the laboratory. Third, unlike many other sharks, the lemon shark has well-developed gill muscles that allow it to respire without continuous swimming movements. This means that lemon sharks can be conditioned and otherwise tested in a fairly restricted environment. Fourth, the lemon shark has a well-developed visual system (e.g., Gruber, Hamasaki, \& Bridges, 1963; Hamasaki \& Gruber, 1965; O'Gower \& Mathewson, 1967) that has been sufficiently studied to permit the selection of appropriate CSs. Finally, the presence of a nictitating membrane that responds discretely to a brief electric shock allows for the easy

This study was supported by Contract No. N0014-67-0201-0013 between the Office of Naval Research and the University of Miami and by National Science Foundation Research Grant GB-24713. Requests for reprints should be sent to Samuel H. Gruber, Division of Biology and Living Resources. Rosenstiel School of Marine and Atmospheric Sciences, University of Miami, Miami, Florida 33149. monitoring of a discrete response. The nictitating membrane response of the lemon shark is also of particular interest, because it appears to be physiologically similar to the nictitating membrane response of the rabbit, which has been much studied in classical conditioning experiments (e.g., Gormezano, Schneiderman, Deaux, \& Fuentes, 1962; Powell, Schneiderman, Elster, \& Jacobson, 1971).

The nictitating membrane is an opaque third eyelid. It is found in several genera of sharks including the lemon shark. While the upper and lower eyelids of sharks are relatively immobile, the nictitating membrane can be drawn across a considerable portion of the eyeball. This nictitating membrane moves upwards and backwards from the lower anterior margin of the eye (Gilbert \& Oren, 1964). A special muscle used to extend the membrane was first described by Johannes Müller (1843). This muscle, the levator palbebrae nictitans, is innervated by cranial nerve III, the facial nerve. In the present experiment, extensions of the nictitating membrane were recorded as CRs and URs. Illumination of a ground glass screen was the CS and a brief electric shock was the US. Besides the conditioning group, several control groups were used to assess whether the nictitating membrane response obtained during the presentation of the CS could be attributed to sensitization, to pseudoconditioning, or to some other nonassociative factor.

\section{METHOD}

\section{Subjects}

The subjects were 20 immature male and female lemon sharks Negaprion brevirostris (Poey), approximately $80 \mathrm{~cm}$ in total length and $2 \mathrm{~kg}$ in weight. They were collected in Biscayne and Florida bays by a private contractor and transported 

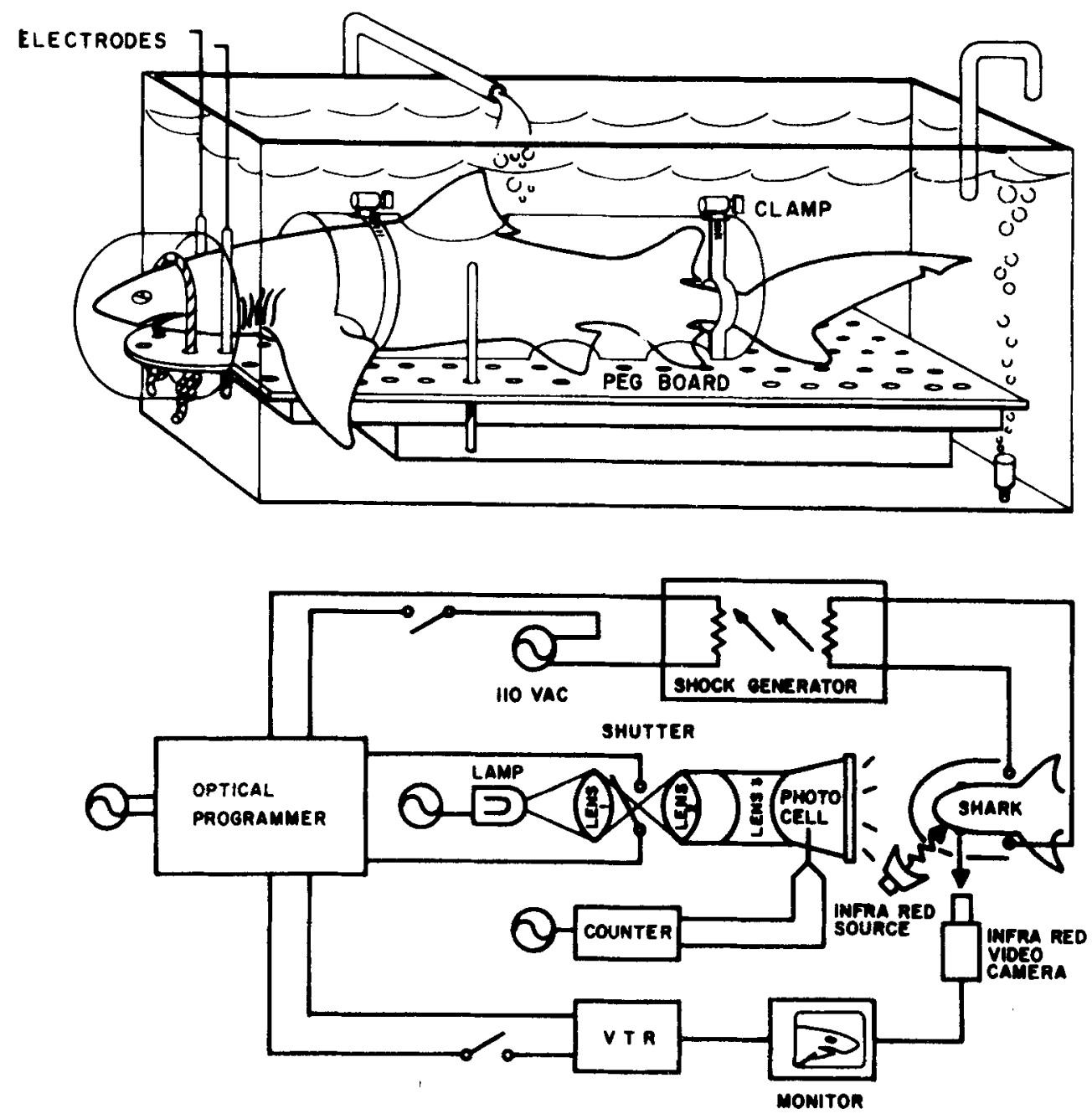

Figure 1. The apparatus in which the sharks were restrained (upper frame) and the stimulation and recording equipment (lower frame). Abbreviation: VTR = video tape recorder.

to holding pens in the laboratory. Once the sharks began eating $.5-1.0 \mathrm{~kg}$ or more of whole fish per week for at least 2 weeks, and otherwise appeared to be in good health, they were ready to be placed in the experimental tank. The experimental and holding tanks were connected to an open system that provided clear running seawater.

\section{Apparatus}

The upper portion of Figure I shows the manner in which the sharks were restrained during experimental sessions. A semirigid plastic tube covering the body from tail to pectoral fins was fastened by two stainless steel clamps. A wooden die immobilized the caudal peduncle. The shark and tube were placed on a pegboard and Plexiglas pegs were used to prevent lateral movements. A nylon line fastened loosely across the head to the pegboard limited vertical movement of the head. The animal and pegboard were placed in a polyester-coated wooden box fitted on one end with a blown acrylic hemisphere. This box and the hemisphere were filled with running seawater. The box was $97 \mathrm{~cm}$ long, $50 \mathrm{~cm}$ wide, and $55 \mathrm{~cm}$ deep. Diameter of the hemisphere was $20 \mathrm{~cm}$.

The lower portion of Figure 1 shows some of the important features of the stimulating and recording apparatus. Source of radiant energy for the CS was a tungsten-halogen lamp (Sylvania
$600 \mathrm{~W}, \mathrm{FAD}, 3,200^{\circ} \mathrm{K}$ ) operated with controlled line voltage (Sola constant-voltage transformer) of $118 \mathrm{~V}$. Light was projected through an optical system onto a ground glass screen. The circular CS was $20 \mathrm{~cm}$ in diam and was located $80 \mathrm{~cm}$ from the shark. Illuminance was $671 \mathrm{fc}$, as measured by a Macbeth illuminometer. Duration of CS stimulation, which was always $.5 \mathrm{sec}$, was controlled by a Packard-Ideal silent leaf-type shutter in conjunction with a Stoelting multichannel optical programmer. The sound of the shutter and ancillary laboratory sounds were masked by running bubbling water in the experimental tank and by the white noise created by high-pressure air cooling of the lamp. Stray light was eliminated by a series of light baffles. The US, administerce by an ac autotransformer, was a 1 - to $3-\mathrm{V}$, 10- to $100-\mathrm{mA}$.1-sec-duration electric shock delivered as an clectric field between two electrodes situated under seawater about $1 \mathrm{~cm}$ away from each side of the shark's head. The electrodes were constructed of brass rods that were $10 \mathrm{~cm}$ long and $8 \mathrm{~mm}$ in diam. During the course of each experimental session, the Sloelting multichannel optical programmer controlled the type of stimuli presented on each trial, the number of trials, and the durations of the CS. US, intertrial interval and CS-US interval.

Responses were monitored using a Craig Model 6410 video camera, recorder, and monitor. Since the sharks were run in 
darkness, a silicon vidicon tube (Texas Instrument Corporation) sensitive to infrared illumination was used in place of the standard vidicon tube. Emitting diodes (Texas Instrument Corporation, TI XL 27) provided the infrared illumination.

\section{Response Measurements}

After the experiment was run. the videotape of each experimental session was played back in stop frame mode and observed on the monitor. Response latencies were calculated by counting the number of 16 -msec-duration video fields that occurred before the onset of a nictitating membrane response. The first nictitating membrane response occurring within the $400 \mathrm{msec}$ following CS onset was detined as a CR except in the case of a control group receiving presentations of neither the CS nor US. In this group, responses occurring during time periods corresponding to the CS duration in the other groups were assessed. Since more than a single detectable response never occurred in any group during the $400 \mathrm{msec}$ following CS onset, the problem of assessing multiple responses was averted. The data were scored by a person who was unfamiliar with the objectives of the experiment.

\section{Procedure}

Twenty lemon sharks were randomly assigned to four groups with the restriction that five sharks were placed in each group. All groups received 7 days of acquisition. Immediately prior to the first acquisition session, each shark was adapted to the experimental apparatus for $10 \mathrm{~min}$. The animals in one control group (Group No-Stim) were individually placed in the experimental chamber and observed for 50-min periods daily to determine rate of spontaneous blinking. The animals in a second control group (Group CS-A) received presentations of the CS alone, and the animals in the third control group (Group CS \& US R) received completely random presentations of the CS and US (Rescorla, 1967). The fourth group (Group CS-US) was the classical conditioning group; it received paired presentations of the CS and US at a CS-US interval of .4 sec. Groups CS-US and CS-A received 100 acquisition trials/day at randomized intertrial intervals of 25,30 , and $35 \mathrm{sec}(\overline{\mathrm{X}}=30 \mathrm{sec})$. The session length for Group CS \& US R was the same as for Groups No-Stim, CS-A, and CS-US; but the $100 \mathrm{CR}$ presentations and 100 US presentations were programmed to occur randomly throughout each session. Shock intensity was varied both within and between groups so as to maintain a uniform extension of the nictitating membrane across the eyeball as the UR. Following acquisition training, Group CS.US received $100 \mathrm{CS}$-alone trials/day for 6 days at the same intertrial intervals used during acquisition.

\section{RESULTS AND DISCUSSION}

The sharks in the No-Stim control group almost never blinked during the 50-min acquisition sessions. Unlike terrestrial vertebrates, sharks have no need of blinking to keep their corneas moist. Number of acquisition responses in each control group during every acquisition day was less than $1 \%$. The finding that the sharks in the CS-A and CS\& US R control groups did not make acquisition responses indicates that acquisition responses observed in Group CS-US could not be attributed to sensitization or pseudoconditioning (Gormezano, 1966; Schneiderman, 1973).

During eyelid conditioning of humans, unconditioned eyeblink responses are observed when a light CS is presented to a dark-adapted subject. This response, called

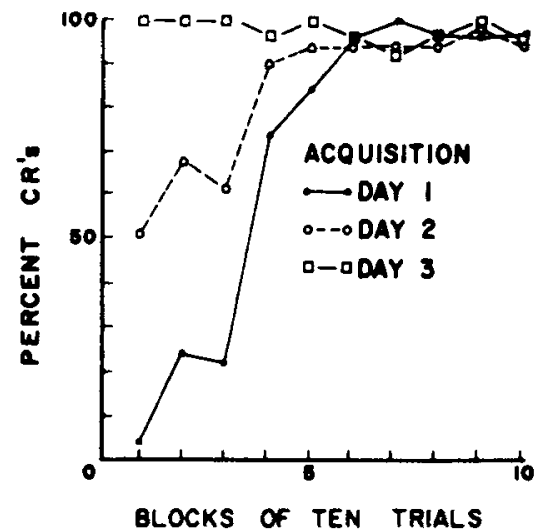

Figure 2. Percentage of nictitating membrane CRs in the experimental group during successive blocks of 10 trials in the first three acquisition sessions.

a beta response, is easily confounded with the CR (Grant, 1945; Grant \& Norris, 1947). The finding that the dark-adapted sharks in Groups CS-A and CS \& US R did not make unconditioned responses to the CS indicates that CRs observed in Group CS-US were not confounded with beta-type responses. Another finding obtained from the CS \& US R control group was that the UR invariably occurred within the first $16-\mathrm{msec}$ videoframe occurring after US onset.

Figure 2 shows the percentage of nictitating membrane CRs obtained by Group CS-US during successive blocks of 10 trials during the first 3 days of acquisition training. Group CS-US acquired the nictitating membrane CR within the first acquisition session and reached a level exceeding 95\% CRs throughout the second half of this first session. During the first trial block of 10 trials in the second acquisition session, the mean level of responding was only $50 \%$. Two of the five sharks (data for individual animals are not shown), however, showed $100 \%$ responding during this trial block, indicating that these sharks retained the CR over the 24-h period between sessions without additional training. In contrast to the high percentage of CRs shown by these two animals, one shark with $93 \%$ CRs during the last 60 trials of Acquisition Session I failed to respond during the first trial block of the second session and revealed only $7 \%$ CRs during the first 30 trials of the second session. Figure 2 indicates that by Day 3 all sharks showed better than $95 \%$ CRs. This level of responding was maintained during each of Acquisition Sessions 4 through 7 (not shown).

Because the sharks in the control groups revealed a preponderance of $0 \%$ CRs during each acquisition session, nonparametric statistics were used to compare the percent CRs of the experimental and control groups. A Kruskal-Wallis one-way analysis of variance conducted upon the percent CRs of the experimental and control groups throughout acquisition confirmed the presence of reliable differences among groups, $H(3)=11.5$, $\mathrm{p}<.01$. A Mann-Whitney U test comparing the per- 


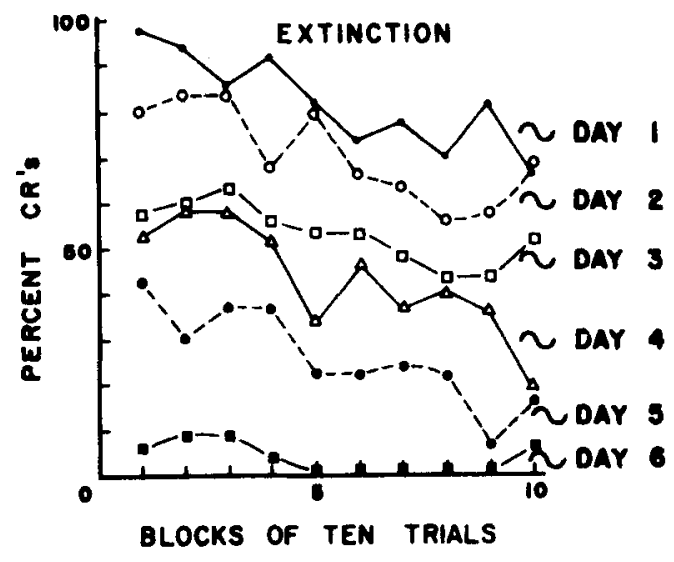

Figure 3. Percentage of nictitating membrane CRs in the experimental group during successive blocks of 10 trials in each extinction session.

formance between Group CS-US and Group CS \& UR R confirmed the presence of reliable differences between the experimental and the control group $(p<.01)$.

Figure 3 shows the percentage of nictitating membrane CRs obtained by Group CS-US during successive blocks of 10 trials in each extinction session. During the first extinction session, the percentage of CRs gradually decreased from $98 \%$ during the first block of 10 trials to $66 \%$ during the last block. The finding that subjects made more CRs during the first block of Extinction Day 2 than they did during the last block of Extinction Day 1 provides an example of spontaneous recovery (Pavlov, 1927, p. 58) and is consistent with previous findings of such recovery for the nictitating membrane $\mathrm{CR}$ in the rabbit (Schneiderman \& Gormezano, 1964). Figure 3 shows that extinction occurred gradually, both

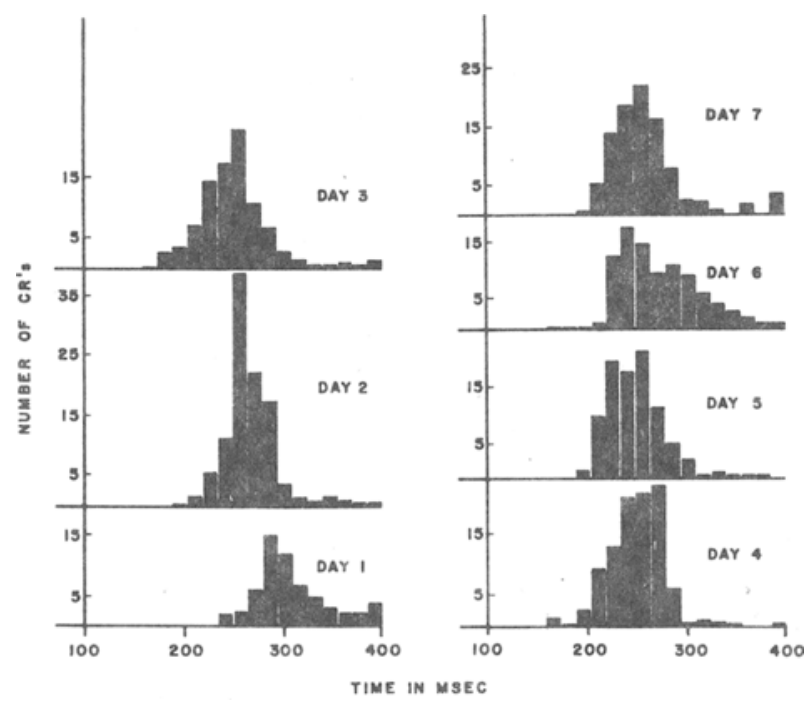

Figure 4. Mean frequency distribution of CR latencies in milliseconds for Group CS-US during the 7 days of acquisition. within and across sessions. Analysis of variance confirmed that percentage CRs decreased reliably across extinction sessions, $F(5 / 20)=13.12, p<.001$. The finding in the presert study that extinction of the nictitating membrane CR in the shark occurred in a gradual manner agrees with the previous report that extinction of the nictitating membrane CR of the rabbit also occurs gradually (Gormezano et al., 1962).

Figure 4 shows the mean latency distributions of CRs for Group CS-US during acquisition. Mean latency decreased from a high of $304 \mathrm{msec}$ on Day 1 of acquisition to $246 \mathrm{msec}$ during the last four acquisition sessions. Analysis of variance confirmed that mean latency decreased significantly across acquisition sessions, $F(6,24)=8.25, p<.001$. The decrease in response latency during acquisition training has also been reported for the nictitating membrane of the rabbit (Gormezano et al., 1962).

The major finding of the present experiment was that classical conditioning of the nictitating membrane response occurred reliably in the lemon shark when a visual stimulus was the CS and electric shock was the US. A high level of conditioning occurred within a single session and stabilized at about $95 \%$ CRs by the second half of the second acquisition session. These CRs were not confounded with pseudoconditioned, sensitized, or other nonassociative responses. The finding of stable, highly reliable CRs in a response system similar to that of the rabbit makes the nictitating membrane response of the lemon shark an ideal vehicle for comparisons of classical conditioning between fish and mammals. Observations in the present experiment that darkadapted restrained lemon sharks reliably conditioned to a visual CS also suggest that the present preparation could be useful for studying sensory psychophysics in these animals. Similarly, the finding that conditioning occurred within a single experimental session suggests that the present preparation could profitably be used in neurophysiological experiments in which classical conditioning would be analyzed by extracellular recording techniques.

\section{REFERENCES}

Aronson, L. R., Aronson, F. R., \& Clark, E. Instrumental conditioning and light-dark discrimination in young nurse sharks. Bulletin of Marine Science, 1967, 17, 249-256.

Clark, E. Instrumental conditioning of lemon sharks. Science, 1959. 130, 217-218.

Gilbert, P. W., \& Oren, M. E. The selachian nictitans and subocular fold. Copeia, 1964, 3, 534-535.

Gormezano. I. Classical conditioning. In J. B. Sidowski (Ed.), Experimental methods and instrumentation in psychology. New York: McGraw-Hill, 1966, 385-420.

Gormezano. I. Schneiderman, N., Deaux, E., \& Fuentes, I. Nictitating membrane: Classical conditioning and extinction in the albino rabbit. Science, 1962, 138, 33-34.

Graeber. R. C., \& Ebbeson, S. D. E. Visual discrimination learning in normal and tectal-ablated nurse sharks (Ginglymostuma cirratum). Comparative Biochemistry and Physinlogy, 1972, 40,121-139. 
GraNt, D. A. A sensitized evelid reaction in relation to the conditioned eyelid response. Joumal of Experimental Psichology. 1945. 35. 393-402.

Grant, D. A.. \& Norris. E. B. Eyelid conditioning as influenced by the presence of sensitized beta-responses. Journal of Experimental Psychology. 1947. 37. 423-433.

Grlber, S. H.. Hamasaki. D. I.. \& Bridges. C. D. B. Cones in the retina of the lemon shark (Negaprion brevirostris). Vision Research, 1963. 3, 97.99.

HamasakI. D. I.. \& Grtber. S. H. The photoreceptors of the nurse shark. Ginglymostoma cirratum and the sting ray. Dasiatus savi. Bulletin of Marine Science, 1965. 15. $1051-1059$.

Müller. J. L'ntersuchungen uber die Eingeweide der Fische, Schlufs der vergleichenden Anatomie der Myxinoiden. Abhandlungen der Koniglichen Akademe der Wissenschaften Zu Berlin. Pp. 109-170. 1843.

NELSON. D. R. Hearing thresholds. frequency discriminations and acoustic orientation in the lemon shark. Negaprion brevirostris (Poev). Bulletin of Marine Science, 1967. 17. $71-768$.

OGower. A. K.. \& Mathewson. R. F. Spectral sensitivity and tlicker-fusion frequency of the lemon shark. Negaprion brevirostris, In P. W. Gilbert. R. W. Mathewson. \& O. P. Rall (Eds.). Sharks. skates and rays. Baltimore: Johns Hopkins Press. 196?.

Pavlov. I. P. Condirioned retlexes (translated by G. V. Anrep). London: Oxford Lniversity Press. 1927.

Poweli. D. A., Schneiderman, N., Elster. A. J.. \& JACOBson, A. Differential classical conditioning in rabbits (Onctolugus cuniculus) to tones and changes in illumination. Journal of Comparative and Physiological Psychology. 1971. 76. 267.274 .

Rescorla, R. A. Pavlovian conditioning and its proper control procedures. Psychological Review, 1967, 74, 71-80.

Schneiderman, N. Classical [Pavlovian] conditioning. New Jersey: General Learning Press. 1973.

SchneIderman. N.. \& Gormezano, I. Conditioning of the nictitating membrane of the albino rabbit as a function of the CS-US interval. Joumal of Comparative and Physiological Psychology. 1964. 57. 188-195.

(Received for publication January 29. 1975: revision received April 25. 1975.) 